Wawasan:

Jurnal Kediklatan Balai Diklat Keagamaan Jakarta

PISSN: 2548-9232; ${ }_{\mathrm{E}}$ ISSN: 2775-3573

Volume 2 Nomor 1 Tahun 2021: 92-99

\title{
URGENSI LITERASI DIGITAL BAGI WIDYAISWARA
}

\author{
Ranti Nuranita* \\ Dedi Restendi** \\ ****Balai Diklat Keagamaan Bandung, Indonesia \\ *e-mail: rantinuranita@gmail.com \\ *e-mail:restendidedi@gmail.com
}

\begin{abstract}
The digital era is marked by the shift of mechanical and analog technology to digital technology. The transfer of technology has led to the disruption of human culture. One of them is in the way of thinking and acting, especially for professionals. Today, a professional must have digital literacy competence, namely the ability to access, manage, understand, integrate, communicate, evaluate, and create information safely and precisely through digital technology. Widyaiswara is a related profession. Questions arise related to this, namely, "Why must digital literacy be mastered by widyaiswara, and for what?" A literature review has been conducted on ten journal articles published in Google Scholar to answer these questions. The results of the study concluded that digital literacy competence could answer the challenges of training in terms of the ability to update information, use gadgets and applications as sources of information, process and present information from training teaching materials, and finally, take an essential role in facing the pattern of distance training implementation based on e-learning application with its various sophistications. The results of the review are expected to provide insight and can be used as literature for further research.
\end{abstract}

Keywords: digital literacy; digital technology; widyaiswara; training

\begin{abstract}
Abstrak
Era digital ditandai dengan beralihnya teknologi mekanik dan analog ke teknologi digital. Peralihan teknologi tersebut telah menyebabkan disupsi terhadap budaya manusia. Salah satunya pada cara berpikir dan bertindak khususnya pada para professional. Seorang professional di zaman kini harus memiliki kompetensi literasi digital yaitu kemampuan untuk mengakses, mengelola, memahami, mengintegrasikan, mengkomunikasikan, mengevaluasi, dan menciptakan informasi secara aman dan tepat melalui teknologi digital. Widyaiswara termasuk profesi terkait. Muncu pertanyaan terkait dengan hal itu yaitu "Mengapa digital literasi harus dikuasai oleh widyaiswara, dan untuk apa?" Untuk menjawab pertanyaan tersebut telah dilakukan sebuah literature review terhadap 10 artikle jurnal yang teruat di Google Scholar. Hasil riview disimpulkan bahwa kompetensi literasi digital dapat mejawab tantangan kepelatihan di era dalam hal kemampuan update informasi, menggunakan gadget dan aplikasi sebagai sumber informasi, mengolah dan menyajikan informasi yang berupa materi bahan ajar pelatihan yang sesuai dengan kultur peserta di era digital dan terakhir mengambil peranan penting dalam menghadapi pola penyelenggaraan pelatihan jarak jauh yang berbasis aplikasi e-learning dengan berbagai kecanggihannya. Hasil riview diharapkan dapat memberikan wawasan dan dapat dijadikan literatur untuk penelitian berikutnya.
\end{abstract}

Kata Kunci: literasi digital; teknologi digital; widyaiswara; pelatihan 


\section{PENDAHULUAN}

Menurut UNESCO yang dikutip Law et.al. (2018), literasi digital didefinisikan sebagai kemampuan untuk mengakses, mengelola, memahami, mengintegrasikan, mengkomunikasikan, mengevaluasi, dan menciptakan informasi secara aman dan tepat melalui teknologi digital yang meliputi kompetensikompetensi yang beragam seperti literasi komputer, literasi ICT, literasi informasi, dan literasi media. Pendapat lain dikemukakan oleh Paul Gilster (1997) yang mengemukakan bahawa literasi digital adalah kemampuan seseorang dalam memafaatkan informasi dalam berbagai bentuk. Baik itu dari sumber perangkat komputer ataupun dari ponsel.

Era digital ditandai dengan beralihnya teknologi mekanik dan analog ke teknologi digital (Kemendikbub, 2016) dan terus berkembang sampai detik ini. Pandangan serupa dikemukakan oleh FA Gustiani (2019) bahwa pada era digital muncul media baru seperti jaringan internet dan telepon pintar yang memanjakan penggunanya untuk mengakses informasi kapanpun dan dimanapun. Telepon pintar yang sudah menjadi kebutuhan pokok hari ini juga memudahkan pengguna untuk berkomunikasi dan sharing informasi melalui berbagai ragam platform aplikasi populer.

Kehadiran internet, search engine dan berbagai aplikasi media social telah membuat siapa saja mudah memperoleh informasi apapun tanpa adanya filter yang menjamin keshahihan informasi tersebut. Era digital menyimpan berbagai potensi dan dampak bagi manusia, dan teknologi digital akan terus bergerak seiring dengan kehidupan umat manusia. Era digital bukan persoalan siap atau tidak dan bukan pula suatu opsi namun sudah merupakan suatu konsekuensi Maka tidak ada pilihan lain selain menguasai dan mengendalikan teknologi dengan baik dan benar agar memberi manfaat yang sebesar besarnya.

Era digital dalam persfektif pembelajaran orang dewasa dimana peserta pelatihan sebagai subjek atau pembelajar yang tumbuh dan berkembang pada suaratu era dimana informasi mengenai ilmu pengetahuan dan teknologi dengan mudah dapat diperoleh dari berbagai sumber yang tak terbatas menuntut widyaiswara untuk mengimbangi atau bahkan lebih awal mengupdate informasi. Sangat dimungkinkan informasi yang diperoleh peserta pelatihan dalam era digital ini lebih akurat, luas dan lebih mempengaruhi pengetahuan, keterampilan dan sikap peserta jika dibandingkan dari informasi yang diperoleh dari kegiatan pelatihan.

Karakteristik pembelajaran orang dewasa dengan dengan "kekhasan" orang dewasanya juga menjadi variabel tersendiri yang harus diperhatikan oleh widyaiswara. Kekhasan yang dimaksud di sini adalah mengacu kepada prinsip orang dewasa hanya mau belajar jika ilmu itu secara instan bermanfaat bagi dirinya. Selain itu orang dewasa cenderung memilih aktivitas belajar yang disukai dan lingkungan belajar yang disenangi berlangsung secara informal.

Dalam kaitannya dengan variabel-variabe tersebut kemampuan 
widyaiswara untuk melayani belajar dan mengimbangi agar pengetahuan dan keterampilan widyaiswara selalu up to date maka widyaiswara harus memiliki kemampuan mencari, memilih, mengolah dan menyajikan informasi menggunakan perangkat digital untuk kepentingan pembelajaran yang bermutu dan sesuai dengan kebutuhan pesserta. Kemempuan tersebut disebut literasi digital.

Isu mengenai urgentsi literasi digital sebagai sebuah kompetensi baru di era industry 4.0 merebak ke semua aspek kihidupan dan profesi. Tentu saja termasuk didalmnya profesi widyaiswara.

Urgensi penguasaa literasi digital bagi widyaiswara tentu tidak diragukan. Namun harus dijelaskan lebih lanjut mengenai alasan dasar pentingnya dan untuk kepentingan apa.

Untuk menjawab pertanyaan tersebut telah dilakukan literature riview unruk menkawab dua pertanyaan berikut: Pertama, mengapa literasi digital perlu dikuasai oleh widyaiswara? Kedua, untuk apa kompetensi tersebut dimanfaatkan dala pekerjaan sebagai widyaiswara?

Artikle ini adalah laporan dari hasil literature riview yang telah dilakukan peneliti. Diharapkan dapat dimanfaatkan oleh pihak terkait dan dapat dijadikan literatur untuk penelitian-penelitian berikutnya.

\section{METODE}

Penelitian ini menggunakan Literature Review atau tinjauan pustaka. Penelitian kepustakaan atau kajian literatur (literature review, literature research) merupakan penelitian yang mengkaji atau meninjau secara kritis pengetahuan, gagasan, atau temuan yang terdapat di dalam tubuh literatur berorientasi akademik (academic-oriented literature), serta merumuskan kontribusi teoritis dan metodologisnya untuk topik tertentu, Cooper (2010)

Adapun sifat dari penelitian ini adalah analisis deskriptif, yakni penguraian secara teratur data yang telah diperoleh yang berupa artikel dalam jurnal elektonik kemudian diberikan pemahaman dan penjelasan agar dapat dipahami.

Intervensi dalam proses review atau penelaahan pada penelusuran ilmiah ini adalah urgensi literasi digital. Strategi pencarian literature dilakukan dengan cara melakukan penelusuran artikel yang terdapat dalam jurnal online melalui google scholar dengan kata kunci yang diplih yaitu literasi digital baik dalam bahasa Indonesia maupun bahasa Inggris. Artikel dalam jurnal elektronik yang sesuai dengan kriteria diambil untuk kemudian dianalisis. Jurnal yang direview terbitan tahun 2017 sampai tahun 2021 yang dapat diakses dalam format PDF (Portable Digital Format) dengan subjek literasi digital. dari hasil penelusuran artikel yang sesuai dengan kriteria menggunakan google scholar dipilihlah 10 artikel yang sesuai.

Jurnal penelitian yang sesuai dengan kriteria kemudian dikumpulkan dan dibuat ringkasan jurnal meliputi nama peneliti, tahun terbit jurnal, judul penelitian, metode dan ringkasan hasil atau temuan. Ringkasan jurnal penelitian tersebut dimasukan ke dalam tabel sesuai 
dengan format tersebut di atas. Analisis isi jurnal, kemudian dilakukan, jurnal yang direview berdasarkan garis besar atau inti dari penelitian tersebut yang dilakukan dengan mengurai dalam sebuah kalimat kemudian jika sudah terkumpul kemudian dicari persamaan dan perbedaan pada masing-masing penelitian lalu dibahas untuk menarik kesimpulan.

\section{HASIL DAN PEMBAHASAN}

Penalaahan terhadap 10 artikel yang berhubungan dengan urgensi dliterasi digital diperoleh jawaban bahwa literasi digital menjadi salah satu kompetensi yang sangat urgen dimiliki seorang widyaiswara dalam era disrupsi teknologi informasi dan komunikasi saat ini dan di masa yang akan datang. Widyaiswara sebagai sebuah profesi dintutut untuk memiliki kompetensi mengakses, mengelola, memahami, mengintegrasikan, mengkomunikasikan, mengevaluasi, dan menciptakan informasi dalam ruang lingkup kegiatan pelatihan.

$$
\text { Kompetensi literasi digital }
$$
tersebut akan menjadi bekal bagi widyaiswara dalam menghadapi berbagai tantangan kepelatihan seperti; (1) Tuntutan untuk update informasi yang harus lebih awal dari peserta, (2) Menguasi berbagai perangkat atau gadget dan aplikasinya, (3) Mengolah informasi yang berupa materi bahan ajar kedalam format yang sesuai dengan kecenderungan prilaku dan kultur peserta yang hidup, tumbuh dan berkembang dalam era disrupsi teknologi informasi dan komunikasi dengan "kekhasan" pendidikan orang dewasa nya dan terakhir (4) Berperan aktif dalam transformasi penyelenggaran pelatihan klasikal yang menuju kearah pelatihan yang diselenggarakan secara jarak jauh melalui berbagai aplikasi e leraning.

Berikut 10 artikel terkait literasi digital hasil penelusuran melalui google scholar dan kesimpulannya.

1. H Anggraeni, (2019), Penguatan Blended Learning Berbasis Literasi Digital dalam Menghadapi Era Revolusi Industri 4.0: Model pembelajaran Blended Learning berbasis literasi digital dipandang sebagai langkah strategis dan inovatif dalam mendesain sistem dan pola pendidikan masa depan menghadapi arus disrupi budaya masyarakat yang berkembang secara massif di era industri 4.0.

2. E. Nurjanah, A. Rusmana, and A. Yanto, (2017), Hubungan

Literasi Digital dengan Kualitas enggunaan E-Resources. Literasi digital menjadi faktor yang sangat menentukan terhadap tingginya kualitas penggunaan e-resources.

3. Abdul Haliq dan Asih Riyanti (2019), Pembelajaran Mandiri Melalui Literasi Digital Literasi digital memberi peluang kepada peserta didik untuk memanfaatkan teknologi dalam mengakses dan memilah informasi yang dibutuhkan

4. A Sujana dan D Rachmatin (2019), Literasi digital abad 21 bagi mahasiswa PGSD: apa, mengapa, dan bagaimana. Melalui literasi digital memungkinkan setiap seorang dapat mengakses informasi secera efektif dan efisien, melakukan penilaian terhadap informasi secara kritis, serta 
menggunakan informasi tersebut secara lebih bermanfaat.

5. F Giovanni, N Komariah (2020), Hubungan Antara Literasi Digital Dengan Prestasi Belajar Siswa Sma Negeri 6 Kota Bogor.

6. M Prihatini, A Muhid (2021), Literasi Digital terhadap Perilaku Penggunaan Internet Berkonten Islam di Kalangan Remaja Muslim Kota. Literasi digital secara signifikan memberikan pengaruh positif terhadap perilaku penggunaan internet Terdapat hubungan yang signifikan antara literasi digital yang meliputi kompetensi informasi, kompetensi komunikasi, kompetensi pembuatan konten, dan kompetensi keamanan dengan prestasi belajar siswa.

7. ZR Landa, T Sunaryo, H Tampubolon (2021), Pengaruh Literasi Digital Guru dan Manajemen Pembelajaran Terhadap Minat Belajar Peserta Didik di SMA Pelita Rantepao: Literasi digital yang dimiliki tenaga pendidik berpengaruh secara positif terhadap minat belajar peserta didik

8. SIGA, Agustinus $\mathrm{Bu}^{\prime} \mathrm{u}$ Araujo (2021), Urgensi Literasi Digital bagi Perkembangan Generasi Milenial. Literasi digital membuat generasi milenial memiliki kemampuan untuk mengaskes informasi, memilah dan memahami bebagai jenis informasi yang ada di media digital secara kritis dan selektif dan kemudian memanfaatkannya dalam konteks pendidikan, pekerjaan, maupun dalam membangun hubungan sosial yang baik dengan siapa saja

9. D Hanelahi, K Atmaja (2020), Literasi digital dalam peningkatan kompetensi peserta didik distance learning di homeschooling: Literasi digital meningkatkan pengetahuan, sikap, minat dan bakat peserta didik dalam mengakses internet, lebih jauh dari itu juga terjadi perubahan sikap yang awalnya meniru segala hal yang ditemui dalam internet menjadi lebih slektif dalam pemilihan konten

10. N Rohmah (2019), Literasi

Digital Untuk Peningkatan Kompetensi Guru Di Era Revolusi Industri 4.0. Literasi digital bagi tenaga pendidik merupakan keniscayaan dalam menggunakan teknologi informasi dan komunikasi untuk membantu dalam melaksanakan tugas dan fungsi secara efektif dan efisien.

A Sujana dan D. Rachmatin (2019) menyimpulkan bahwa Melalui literasi digital memungkinkan setiap seorang dapat mengakses informasi secera efektif dan efisien, melakukan penilaian terhadap informasi secara kritis, serta menggunakan informasi tersebut secara lebih bermanfaat, hal senada dikemukakan oleh SIGA, Agustinus Bu'u Araujo (2021) dari hasil penelitiannya menyatakan bahwa Literasi digital membuat generasi milenial memiliki kemampuan untuk mengaskes mengakses informasi, memilah dan memahami bebagai jenis informasi yang ada di media digital secara kritis dan selektif dan kemudian 
memanfaatkannya dalam konteks pendidikan, pekerjaan, maupun dalam membangun hubungan sosial yang baik dengan siapa saja.

Dalam konteks widyaiswara dan peserta pelatihan jelas bahwa widyaiswara memiliki kesempatan yang sama dalam mengaupdate informasi melalui penguasaan berbagai jenis gadget seperti komputer dan smartphone (jangan ketinggalan oleh peserta) karena disisi lain peserta pelatihan dari generasi milenial sudah memiliki kemampuan untuk mengakses, memilihan dan memilih informasi dari media digital yang sesuai dengan kebutuhannya.

M Prihatini dan A Muhid (2021) dalam penelitiannya menyatakan bahwa Literasi digital secara signifikan memberikan pengaruh positif terhadap perilaku penggunaan internet, pendapat serupa dikemukakan oleh D Hanelahi dan K Atmaja (2020) yang menyatakan bahwa Literasi digital meningkatkan pengetahuan, sikap, minat dan bakat peserta didik dalam mengakses internet, lebih jauh dari itu juga terjadi perubahan sikap yang awalnya meniru segala hal yang ditemui dalam internet menjadi lebih slektif dalam pemilihan konten. Hasil penelitian yang sama dikemukakan oleh Abdul Haliq dan Asih Riyanti (2019) yang menyatakan bahwa Literasi digital memberi peluang kepada peserta didik untuk memanfaatkan teknologi dalam mengakses dan memilah informasi yang dibutuhkan. ketiga penelitian ini memberikan gambaran bahwa peserta pelatihan sebagai pembelajar memiliki kecenderungan menyukai konten yang bersumber dari internet dan mampu memilih mana konten yang bermanfaat bagi dirinya, maka dari itu kemampuan menyajikan informasi yang berupa materi ajar yang dibuat widyaiswara harus mengikuti kecenderungan tersebut.

Kualitas konten materi bahan ajar pelatihan harus benar - benar diperhatikan mengingat cara belajar peserta pelatihan sebagai orang dewasa yang hanya akan belajar apabila bermanfaat bagi dirinya. Melalui kompetensi literasi digital tanatangan tersebut dapat menemukan solusinya, hal tersebut senada dengan yang dikemukakan oleh E. Nurjanah, A. Rusmana, and A. Yanto (2017) yang dalam penelitiannya menyatakan bahwa Literasi digital menjadi faktor yang sangat menentukan terhadap tingginya kualitas penggunaan $e$ resources.

Keberhasilan program pelatihan dapat dilihat dari terjadinya perubahan dalam hal pengetahuan, keterampilan dan perilaku peserta yang berhubungan dengan tugas dan fungsinya. Perubahan ketiga ranah tersebut sebagai hasil dari pelatihan hanya akan terjadi apabila adanya minat dan kebutuhan peserta dengan gaya belajar orang dewasa. Melalui literasi digital yang dimiliki widyaiswara tujuan pelatihan tersebut akan mudah dicapai, hal ini sesuai dengan hasil penelitian yang dikemukakan oleh ZR Landa, T Sunaryo dan H Tampubolon (2021) yang menyatakan bahwa Literasi digital yang dimiliki tenaga pendidik berpengaruh secara positif terhadap minat belajar peserta didik. Temuan penelitian ini juga diperkuat oleh $\mathrm{F}$ Giovanni dan N Komariah (2020) melalui penelitiannya menyatakan 
bahwa Terdapat hubungan yang signifikan antara literasi digital yang meliputi kompetensi informasi, kompetensi komunikasi, kompetensi pembuatan konten, yang dimiliki tenaga pendidik dengan prestasi belajar peserta didik

Terakhir,

Penyelenggaraan pelatihan dimasa yang akan datang akan diselenggarakan secara jarak jauh melalui berbagai aplikasi e leraning dengan prinsip efektif dan efisien, literasi digital yang dimiliki widyaiswara akan sangat bermanfaat dalam menghadapi transformasi tersebut, hal ini sebagaimana dikemukakan oleh N Rohmah (2019) yang menyatakan bahwa Literasi digital bagi tenaga pendidik merupakan keniscayaan dalam menggunakan teknologi informasi dan komunikasi untuk membantu dalam melaksanakan tugas dan fungsi secara efektif dan efisien. Pernyataan tersebut diperkuat oleh H Anggraeni (2019) yang menyatakan bahwa Model pembelajaran Blended Learning sebagai salah satu model pembelajaran jika diselenggarakan berbasis literasi digital dipandang sebagai langkah strategis dan inovatif dalam mendesain system dan pola pendidikan masa depan menghadapi arus disrupi budaya masyarakat yang berkembang secara massif di era industri 4.0

\section{KESIMPULAN}

Dari hasil review terhadap 10 artikel dalam jurnal elektronik ditemukan fakta yang dapat dirumuskan menjadi kesimpulan sebagai jawaban dari penelitian ini bahwa literasi digital bagi pemangku jabatan widyaiswara sangatlah urgen. Kompetensi literasi digital dapat mejawab tantangan kepelatihan di era dalam hal kemampuan update informasi, menggunakan gadget dan aplikasi sebagai sumber informasi, mengolah dan menyajikan informasi yang berupa materi bahan ajar pelatihan yang sesuai dengan kultur peserta di era digital dan terakhir mengambil peranan penting dalam menghadapi pola penyelenggaraan pelatihan jarak jauh yang berbasis aplikasi e-learning dengan berbagai kecanggihannya.

Hasil penelitian ini dapat menjadi salah satu rujukan bagi Balai Diklat Keagamaan Bandung dalam rangka meningkatkan kompetensi literasi digital untuk jabatan fungsional widyaiswara.

\section{DAFTAR PUSTAKA}

Anggraeni, H. (2019). Penguatan Blended Learning Berbasis Literasi Digital dalam Menghadapi Era Revolusi Industri 4.0. Al-Idarah: Jurnal Kependidikan Islam, 9(2): 190-203.

Gilster, P., \& Glister, P. (1997). Digital literacy. New York: Wiley Computer Pub.

Giovanni, F., \& Komariah, N. (2020). Hubungan Antara Literasi Digital Dengan Prestasi Belajar Siswa Sma Negeri 6 Kota Bogor. LIBRARIA: Jurnal Perpustakaan, 7(1): 147.

Gustiani, F. A. (2019). Pengaruh locus of control dan academic motivation terhadap adiksi media sosial pada Mahasiswa (Doctoral dissertation, UIN Sunan Gunung Djati Bandung). 
Haliq, A., \& Riyanti, A. (2019). Pembelajaran Mandiri melalui Literasi Digital.

Kemendikbud, 2016. Panduan Gerakan Literasi Sekolah.

Landa, Z. R., Sunaryo, T., \& Tampubolon, H. (2021). Pengaruh Literasi Digital Guru dan Manajemen Pembelajaran Terhadap Minat Belajar Peserta Didik di SMA Pelita Rantepao. Jurnal Cendekia: Jurnal Pendidikan Matematika, 5(1): 718-734.

Mohammad Imam Farisi. 2010. Pengembangan Asesmen Diri Siswa (Student SelfAssessment) sebagai Model Penilaian dan Pengembangan Karakter. Artikel disampaikan pada Konferensi Ilmiah Nasional "Asesmen dan Pembangunan Karakter Bangsa" HEPI UNESA 2012.Konferensi Ilmiah Nasional “Asesmen dan Pembangunan Karakter Bangsa" HEPI UNESA 2012.

Nurjanah, E., Rusmana, A., \& Yanto, A. (2017). Hubungan literasi digital dengan kualitas penggunaan e-resources. Lentera Pustaka: Jurnal Kajian Ilmu Perpustakaan, Informasi Dan Kearsipan, 3(2): 117-140.

Prihatini, M., \& Muhid, A. (2021). Literasi Digital terhadap Perilaku Penggunaan Internet Berkonten Islam di Kalangan Remaja Muslim Kota. Journal An-Nafs: Kajian Penelitian Psikologi, 6(1): 23-40.

SIGA, A. B. U. A. (2021). Urgensi Literasi Digital bagi Perkembangan Generasi Milenial Doctoral dissertation, STFK Ledalero.

Sujana, A., \& Rachmatin, D. (2019). Literasi digital abad 21 bagi mahasiswa PGSD: apa, mengapa, dan bagaimana. In Current Research in Education: Conference Series Journal, 1(1): 003. 